\title{
The Ocean-Land-Atmosphere Model: Optimization and Evaluation of Simulated Radiative Fluxes and Precipitation
}

\author{
David Medvigy, Robert L. Walko, Martin J. Otte, and Roni Avissar \\ Department of Civil and Environmental Engineering, Duke University, Durham, North Carolina
}

(Manuscript received 6 July 2009, in final form 16 October 2009)

\begin{abstract}
This work continues the presentation and evaluation of the Ocean-Land-Atmosphere Model (OLAM), focusing on the model's ability to represent radiation and precipitation. OLAM is a new, state-of-the-art earth system model, capable of user-specified grid resolution and local mesh refinement. An objective optimization of the microphysics parameterization is carried out. Data products from the Clouds and the Earth's Radiant Energy System (CERES) and the Global Precipitation Climatology Project (GPCP) are used to construct a maximum likelihood function, and thousands of simulations using different values for key parameters are carried out. Shortwave fluxes are found to be highly sensitive to both the density of cloud droplets and the assumed shape of the cloud droplet diameter distribution function. Because there is considerable uncertainty in which values for these parameters to use in climate models, they are targeted as the tunable parameters of the objective optimization procedure, which identified high-likelihood volumes of parameter space as well as parameter uncertainties and covariances. Once optimized, the model closely matches observed large-scale radiative fluxes and precipitation. The impact of model resolution is also tested. At finer characteristic length scales (CLS), smaller-scale features such as the ITCZ are better resolved. It is also found that the Amazon was much better simulated at 100- than 200-km CLS. Furthermore, a simulation using OLAM's variable resolution functionality to cover South America with 100-km CLS and the rest of the world with 200-km CLS generates a precipitation pattern in the Amazon similar to the global 100-km CLS run.
\end{abstract}

\section{Introduction}

The Ocean-Land-Atmosphere Model (OLAM) is a new numerical simulation model developed to extend the capabilities of the Regional Atmospheric Modeling System (RAMS) to a global model domain (Walko and Avissar 2008a,b). OLAM's newly developed dynamic core has been shown to realistically represent flows with significant vertical motion in a multilevel atmosphere, including an idealized global circulation, a cold density current, and a mountain-wave flow over an orographic barrier (Walko and Avissar 2008b), and has also been shown to capture the global-scale dynamics represented by the shallow-water equations (Walko and Avissar 2008a).

OLAM's parameterizations of physical processes, initialization methods, and I/O data formats have been

Corresponding author address: Roni Avissar, Rosenstiel School, University of Miami, 4600 Rickenbacker Causeway, Miami, FL 33149.

E-mail: ravissar@rsmas.miami.edu taken from RAMS (Pielke et al. 1992; Cotton et al. 2003). Although these parameterizations have previously been evaluated in the context of RAMS (e.g., Walko et al. 1995; Harrington 1997; Harrington et al. 1999; Nachamkin and Cotton 2000), several factors make it essential to establish their viability when coupled with OLAM's stateof-the-art dynamic core. First, while OLAM's dynamic core has mainly been tested in terms of idealized scenarios, its performance when run together with the full model physics remains unestablished. Second, in limitedarea models like RAMS, the accrual of model errors is limited by the forcing at the lateral boundaries that refreshes the atmospheric state with imported new conditions. However, in global models like OLAM, errors accumulate and can more readily lead to an unrealistic atmospheric state. Finally, global models are more susceptible than limited-area models to difficult-to-decipher teleconnection errors; these occur when an error in one region teleconnects to other locations that may have been otherwise well represented.

Here, we address these issues by using observations to assign values to several empirical parameters of OLAM's 
physics schemes. This task, for OLAM but also for other GCMs (Murphy et al. 2004; Stainforth et al. 2005), is challenging for several reasons: 1) GCMs typically have a large number of empirical parameters, 2) GCMs can be very sensitive to small changes in parameters, 3 ) parameters can exhibit significant covariances, and 4) computational constraints limit the exploration of parameter space. Because of these computational constraints, previous, subjective methods of tuning GCMs were not manifestly optimal.

Another approach has recently been applied to lowresolution GCMs (Jones et al. 2005; Severigns and Hazeleger 2005) and numerical forecast models (Norris and da Silva 2007), in which a formal likelihood function is defined and a numerical algorithm is used to adjust parameters so as to maximize the likelihood. These objective optimizations make automatic the simultaneous optimization of many parameters, assure the best possible match to target datasets, and provide parameter uncertainties and covariances.

We adopt this objective approach here. Given that computational constraints currently prevent us from simultaneously optimizing all of OLAM's empirical parameters, we focus on the essential task of objectively optimizing a subset of parameters enabling accurate simulations of the earth's radiation balance and of precipitation on monthly to decadal time scales. Such metrics are commonly used to evaluate GCMs (Randall et al. 2007; Bender 2008; Shimpo et al. 2008), and practically all GCMs have carried out subjective parameter adjustment to reproduce them (recent examples include Collins et al. 2006 and Delworth et al. 2006).

The target datasets used to constrain the model are discussed in section 2. In section 3, the physical parameterizations are summarized and empirical parameters slated for optimization are identified. Also in this section we describe our maximum likelihood algorithm. Section 4 describes the general model configuration, initialization, and forcings common to all simulations. Section 5 presents the optimized parameters and uncertainties. The model's ability to simulate radiation and precipitation on monthly to decadal scales is analyzed in section 6 . The main conclusions from this work are summarized in section 7.

\section{Datasets}

Remotely sensed radiances have greatly enhanced our understanding of the earth's radiation budget. Campaigns conducted over the past two decades include the Earth Radiation Budget Experiment (ERBE; Ramanathan et al. 1989), which provides satellite-measured top-ofatmosphere (TOA) shortwave and longwave fluxes; the
Earth Radiation Budget Satellite (ERBS; Wielicki et al. 2002), which spans a longer time period than ERBE but is not globally complete; and the Clouds and the Earth's Radiant Energy System (CERES; Wielicki et al. 1996), which has generated TOA fluxes from three different instruments since 1998. While surface (SFC) fluxes cannot be directly measured from space, they have been estimated by the above research groups by using the TOA fluxes and radiative transfer models.

For the purposes of GCM parameter adjustment, the choice of whether to use ERBE, ERBS, or CERES products may not be very significant, as recent work by Bender (2008) reported little difference between models constrained by ERBE or CERES (ERBS was not discussed). In this study, we have used the CERES data to optimize and evaluate OLAM because of its more comprehensive temporal coverage.

To evaluate OLAM's precipitation fields, we used monthly averages of the 1-degree daily (1DD) product, available from October 1996 to the present, from the Global Precipitation Climatology Project (GPCP; Huffman et al. 2001). Strictly speaking, the 1DD product is not data, but rather a gridded analysis product based on satellite estimates of rainfall constrained by a monthly analysis incorporating gauge and satellite observations. The gridded product is subject to random errors (Huffman 1997) and systematic errors. Other gridded precipitation products are available (e.g., Xie and Arkin 1997), and there is continued debate over which is the most realistic (Yin et al. 2004; Guirguis and Avissar 2008).

We constructed 20 target datasets, spanning a range of spatial scales, from the CERES and GPCP data. These consisted of five observables averaged over each of four regions. The observables included upward shortwave and longwave radiation at the top of the atmosphere, downward shortwave and longwave radiation at the surface, and precipitation. Henceforth, we abbreviate upward top of the atmosphere fluxes as "UTOA" and downward surface fluxes as "DSFC." The 4 averaging regions were: global, tropical (latitude between $20^{\circ} \mathrm{S}$ and $20^{\circ} \mathrm{N}$ ), temperate (latitude between $20^{\circ}$ and $65^{\circ} \mathrm{S}$, and between $20^{\circ}$ and $65^{\circ} \mathrm{N}$ ), and polar (latitude poleward of $65^{\circ} \mathrm{N} / \mathrm{S}$ ).

\section{Optimization procedure}

\section{a. Choice of parameters}

The representation of microphysics is highly relevant to the model's ability to simulate radiation and precipitation. The bulk scheme used in OLAM (Walko et al. 1995, 2000a) represents seven different classes of hydrometeors (cloud water, rain, pristine ice, snow, aggregates, graupel, and hail), each defined by a particular set of 
growth mechanisms. Cloud water and pristine ice can nucleate directly from water vapor, while other categories develop from collision and coalescence of preexisting hydrometeors. All hydrometeors experience vapor deposition and evaporation. The hydrometeor size spectra are assumed to follow generalized gamma distribution functions,

$$
n(D)=\frac{N_{t}}{\Gamma(\nu)}\left(\frac{D}{D_{n}}\right)^{\nu-1} \frac{1}{D_{n}} \exp \left(-\frac{D}{D_{n}}\right)
$$

where $n(D)$ is the number concentration of hydrometeors having diameter $D, N_{t}$ is the total number concentration, $\Gamma$ is the gamma function, $\nu$ is the shape parameter, and $D_{n}$ is the characteristic diameter. Note that $N_{t}$ and $D_{n}$ are not independent; for each species, one is specified and the other diagnosed (Walko et al. 1995). In OLAM, we usually specify $N_{t}$ for cloud droplets and $D_{n}$ for other species. In addition, $\nu$ must be specified for all species.

Based on preliminary simulations (section 5e) and the study of Liu and Avissar (1996) who explored the sensitivity of this microphysics parameterization in RAMS, we focus here on two parameters from the parameterization: the width parameter for the size spectrum of cloud droplets ( $\left.\nu_{\text {cloud }}\right)$ and the number of cloud droplets per kilogram of air $\left(N_{t}\right)$. In reality, these parameters exhibit complex spatiotemporal variability depending on cloud condensation nuclei (CCN) size distributions, synoptic conditions, and other factors (cf. Stevens et al. 1998; Jiang et al. 2002). However, modeling this variability can be computationally expensive and often requires $\mathrm{CCN}$ initial conditions that are not readily available; thus, GCM studies often rely on a simpler approach in which these parameters are treated as constants. One weakness of this approach is that the global-scale parameters are not directly measurable-the nonlinearity of microphysical processes makes it difficult to infer appropriate global-scale parameter values from local-scale measurements. Determining what (if any) global-scale parameter values are appropriate for a numerical model is one of the principal aims of this study.

The model configurations that we chose to optimize (Table 1) were developed to investigate impacts of the choice of optimized parameters, the spatial and temporal dependence of parameters, and the impact of model resolution on simulation results. This represents a sampling of possible model configurations and parameter selections, and is not meant to be absolutely comprehensive. Even at the coarser model resolutions, current computational constraints limited us to simultaneously optimizing no more than about two-three parameters over
TABLE 1. Summary of parameter optimizations.

\begin{tabular}{clll}
\hline \hline $\begin{array}{c}\text { Simulation } \\
\text { Name }\end{array}$ & $\begin{array}{c}\text { Parameter } \\
\text { Names }\end{array}$ & $\begin{array}{c}\text { Horizontal } \\
\text { characteristic } \\
\text { Length scale }\end{array}$ & $\begin{array}{c}\text { Simulation } \\
\text { Period }\end{array}$ \\
\hline PO1 & $N_{t}, \nu_{\text {cloud }}$ & $200 \mathrm{~km}$ & October 2001 \\
PO2 & $N_{t}, \nu_{\text {cloud }}$ & $200 \mathrm{~km}$ & January 2002 \\
PO3 & $N_{t}, \nu_{\text {cloud }}$ & $200 \mathrm{~km}$ & April 2001 \\
PO4 & $N_{t}, \nu_{\text {cloud }}$ & $200 \mathrm{~km}$ & July 2001 \\
PO5 & $N_{t}, \nu_{\text {cloud }}$ & $100 \mathrm{~km}$ & October 2001 \\
PO6 & $N_{t}, \nu_{\text {cloud }}$ & $50 \mathrm{~km}$ & October 2001 \\
PO7 & $N_{t, \text { tropical }}$, & $200 \mathrm{~km}$ & October 2001 \\
& $N_{t, \text { extratropical }}$ & $200 \mathrm{~km}$ & October 2001 \\
PO8 & $N_{t, \text { land }}, N_{t, \text { sea }}$ & 200 & \\
\hline
\end{tabular}

a single month. Investigation of other parameters is therefore beyond the scope of this work.

\section{b. Maximum likelihood function}

The method of maximum likelihood (Edwards 1972) was used to determine the set of model parameters most supported by the datasets as well as their uncertainty intervals. For the sake of simplicity, normally distributed errors were assumed for the data points. The model parameters were then chosen so as to maximize the following log-likelihood function $L$ given by

$$
L=\sum_{j=1}^{N_{\text {datasets }}}\left\{\frac{w_{j}}{N_{j}} \sum_{i=1}^{N_{j}}\left[-\frac{1}{2} \log \left(2 \pi \sigma_{i}^{2}\right)-\frac{\left(x_{\mathrm{pred}, i}-x_{\mathrm{obs}, i}\right)^{2}}{2 \sigma_{i}^{2}}\right]\right\},
$$

where $N_{j}$ is the number of observations in dataset $j, \sigma_{i}$ is the uncertainty in element $i$ of dataset $j, x_{\mathrm{obs}, i}$ is the measurement of element $i$ in dataset $j$, and $x_{\mathrm{pred}, i}$ is the model's estimate for element $i$ in dataset $j$. Datasets are assigned weights, $w_{j}$, with the sum of the weights adding up to 1.

The maximum value of the log-likelihood function $L_{\max }$ corresponds to the parameter set that minimizes model-data mismatch. The volume of parameter space defined by $\left(L_{\max }-L\right)<2$ describes the $95 \%$ confidence limit on the parameters (Edwards 1972). However, mere identification of the optimal parameter set does not imply that the degree of mismatch has been reduced to an acceptable level; this must be separately confirmed through model-data comparisons (section 6).

Many numerical algorithms exist for maximizing Eq. (2), including Markov chain Monte Carlo and genetic algorithms (Press et al. 1992). However, any such algorithm would require a priori specification of the weights. We were reluctant to do this because we wanted to see how parameter estimates, uncertainties, and covariances depended on the choice of target datasets. We therefore 
carried out the simplest possible approach, uniformly sampling parameter space to obtain parameter values and then carrying out the corresponding simulations. With these results saved, we afterward mapped out the dependence of the likelihood function on parameter values and dataset weights. Uncertainties introduced by use of a finitesampling interval are discussed further in section 5 .

\section{Simulation protocol}

OLAM uses several parameterizations ported directly from RAMS, including microphysics (Walko et al. 1995), cumulus convection (Grell and Dévényi 2002), radiative transfer (Harrington and Olsson 2001), subgrid-scale turbulence (Lilly 1962; Hill 1974), and land surface (Walko et al. 2000b). All simulations were initialized from $\mathrm{Na}-$ tional Centers for Environmental Prediction-National Center for Atmospheric Research (NCEP-NCAR) reanalysis (Kalnay et al. 1996). Sea surface temperatures were prescribed from the weekly, $1^{\circ}$ maps of Reynolds et al. (2002). The horizontal characteristic length scale (CLS) of the grid mesh ranged from 50 to $200 \mathrm{~km}$ (Table 1). The grid's vertical structure consisted of 53 layers at defined heights, ranging in thickness from $200 \mathrm{~m}$ near the surface to $2000 \mathrm{~m}$ near the model top at $45 \mathrm{~km}$.

\section{Parameter optimization}

\section{a. Baseline optimization}

As a baseline optimization, we carried out 361 simulations to determine the dependence of the likelihood function on the parameters $N_{t}$ and $\nu_{\text {cloud }}$ for the month of October 2001 at a CLS of $200 \mathrm{~km}$. Here $N_{t}$ was sampled evenly in log space at 19 points given by

$$
N_{t}=\left(9.4 \times 10^{6} \mathrm{~kg}^{-1}\right) 2^{0.5(i-1)} \quad i=1,2, \ldots, 19,
$$

and $\nu_{\text {cloud }}$ was sampled evenly according to

$$
\nu_{\text {cloud }}=2+[8 / 9(i-1)] \quad i=1,2, \ldots, 19 .
$$

We first consider a likelihood function with all 20 target datasets (section 2) weighted equally; this is illustrated in Fig. 1a. Notable features include the optimal parameter set (corresponding to the maximum of the likelihood function) and the region of parameter space consistent with the target datasets at the $95 \%$ confidence level (c.l.), corresponding to where the likelihood function was within $2 \log$-likelihood units of its maximum. A strong positive correlation exists between $N_{t}$ and $\nu_{\text {cloud }}$ for small values of $N_{t}$; however, once $N_{t}$ reaches a critical value (about 3-6 $610^{8} \mathrm{~kg}^{-1}$ ), increases in $\nu_{\text {cloud }}$ are no longer capable of compensating for increases in $N_{t}$. This covariance between $N_{t}$ and $\nu_{\text {cloud }}$ has also been seen in data (Gonçalves et al. 2008).

Errors in identifying the $95 \%$ c.l. region of parameter space incurred by the use of a finite sampling interval are comparatively small. Using $25 \%$ of the sampled points [every other point of those defined in Eqs. (2)-(3)], the maximum likelihood score decreases by only $0.09 \log$ likelihood units, which is much smaller than the $2 \log$ likelihood unit threshold used to define the $95 \%$ c.l. region.

The global parameters obtained here are not directly analogous to measurements taken during field campaigns because of the nonlinearity of microphysical processes combined with the real-world spatiotemporal variation of hydrometeor properties. Nevertheless, the results are comparable to previous measurements. For example, recent observations in the Amazon (Gonçalves et al. 2008) found $N_{t}$ varying between $2 \times 10^{8} \mathrm{~kg}^{-1}$ for clean air and $15 \times 10^{8} \mathrm{~kg}^{-1}$ for air heavily influenced by biomass burning; in the arctic, somewhat lower $N_{t}$ values have been observed, ranging from about 0.5 to $5 \times 10^{8} \mathrm{~kg}^{-1}$ (Tsay and Jayaweera 1984). The optimal $\nu_{\text {cloud }}$ value reported here is higher than values used in the past with RAMS (e.g., Meyers et al. 1997) and reported in the Amazon (Gonçalves et al. 2008). However, the relatively large value is not unreasonable (Babb et al. 1999), and of course, lower values of $\nu_{\text {cloud }}$ are consistent with the datasets provided that a sufficiently small $N_{t}$ is used.

\section{b. Role of individual datasets}

Figures 1b-d illustrate how individual target datasets contribute to the overall likelihood function. When the likelihood function is defined solely in terms of UTOA radiative fluxes (Fig. 1b), the datasets with the smallest uncertainties, the parameters are most stringently constrained. However, the area of $95 \%$ confidence and the optimal parameter values are similar to those obtained using the likelihood definition that included all datasets (Fig. 1a).

DSFC radiation is a more processed product than UTOA radiation, and accordingly has larger uncertainty. This translates into larger parameter uncertainty when likelihood is defined solely in terms of the DSFC radiative fluxes (Fig. 1c), assuming similar sensitivities of DSFC and UTOA radiation to parameters. The shape of the likelihood function and the location of the optimum are both similar to when the likelihood function is defined in terms of UTOA fluxes; the contours are merely spaced farther apart. One way to interpret this is to consider the optimization parameters as controlling the degree to which radiation is scattered by clouds. For small $N_{t}$ and large $\nu_{\text {cloud }}$, this process is too weak, DSFC shortwave is too large, and UTOA shortwave is too small (this will be 
(a)

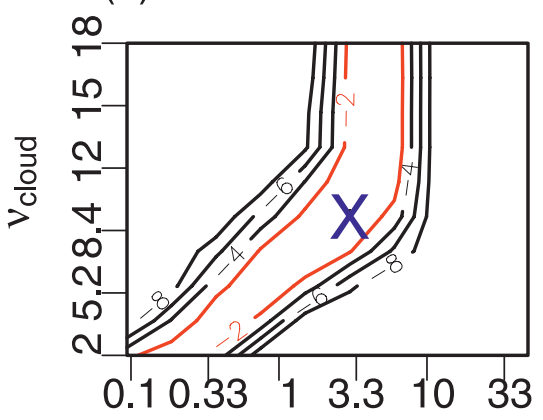

(c)

$\mathrm{N}_{\mathrm{t}}\left(10^{8} \mathrm{~kg}^{-1}\right)$

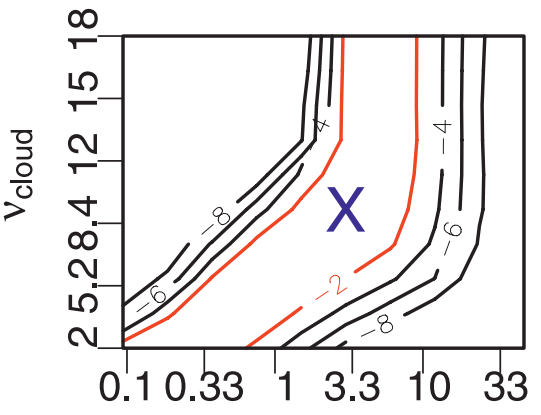

$\mathrm{N}_{\mathrm{t}}\left(10^{8} \mathrm{~kg}^{-1}\right)$ (b)

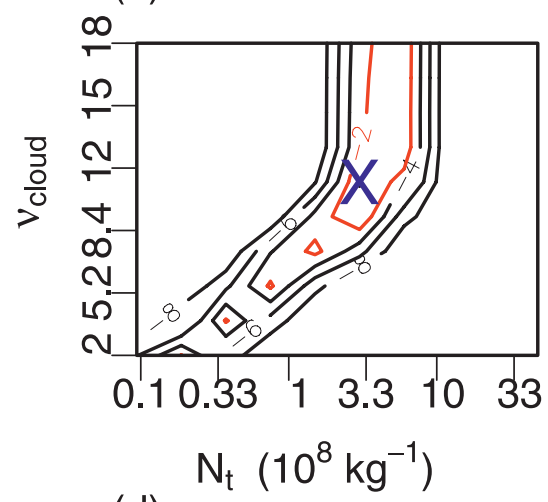

(d)

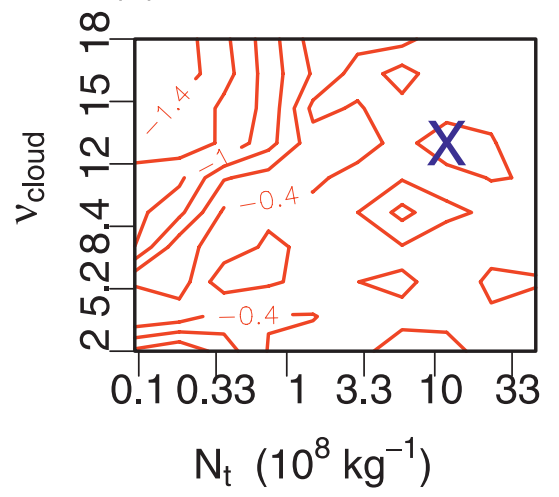

FIG. 1. Maximum likelihood function defined in terms of different datasets. In all cases, the likelihood function is scaled such that a value of 0 corresponds to the optimal parameter values, denoted by the blue X. The region within the red contour denotes the $95 \%$ c.l. Note that $N_{t}$ is plotted on a log scale. Simulations were carried out for October 2001 at $200-\mathrm{km}$ CLS. (a) All datasets used to define the likelihood function. (b) UTOA radiative fluxes used to define the likelihood function. (c) DSFC radiative fluxes used to define the likelihood function. (d) Precipitation used to define the likelihood function. In (d), all shown parameter values fall within the $95 \%$ c.l.

explored further in section 6). The reverse occurs for large $N_{t}$ and small $\nu_{\text {cloud. }}$. Such an outcome is not a priori guaranteed: if the surface albedo is wrong, or if clouds absorb the wrong amount of solar radiation, the likelihood profiles obtained using only UTOA fluxes might differ substantially from those obtained using only DSFC fluxes.

Precipitation is much less sensitive to the microphysics parameters; the entire plotted region falls within the $95 \%$ c.l. when precipitation alone is used to define the likelihood function (Fig. 1d). Part of the reason for this is that only about $1 / 3$ of the precipitation arises from the microphysics, with the remaining $2 / 3$ coming from the convective parameterization. Because the optimized parameters are not directly connected to the convective parameterization, their influence on rainfall is muted. Over longer periods ( $\sim$ months), the impacts of the microphysics parameters on convection would likely become stronger as a result of feedbacks from other factors such as soil moisture.

\section{c. Parameter seasonality}

Additional optimizations were carried out for April 2001, July 2001, and January 2002 (all months of relatively neutral Pacific sea surface temperatures) to investigate the seasonal variability of the parameters. Here, the likelihood function is defined by weighting all 20 datasets equally. As shown in Fig. 2, the 95\% c.l. regions of parameter space obtained from these optimizations are similar to that obtained from the October optimization (Fig. 1a). Optimal parameter values are also similar; July is almost identical to October, while the January and April optimizations both yield slightly higher $\nu_{\text {cloud }}$ values. The small seasonal variation indicated by these results suggests that using parameters from only a single 1-month optimization is sufficient to obtain near-optimal model performance in long-term simulations. This is important because computational constraints prevent us from carrying out parameter optimizations for each 
(a)

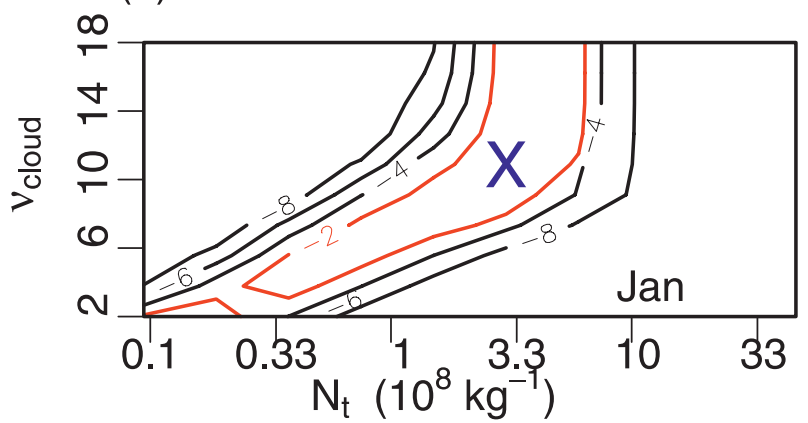

(b)
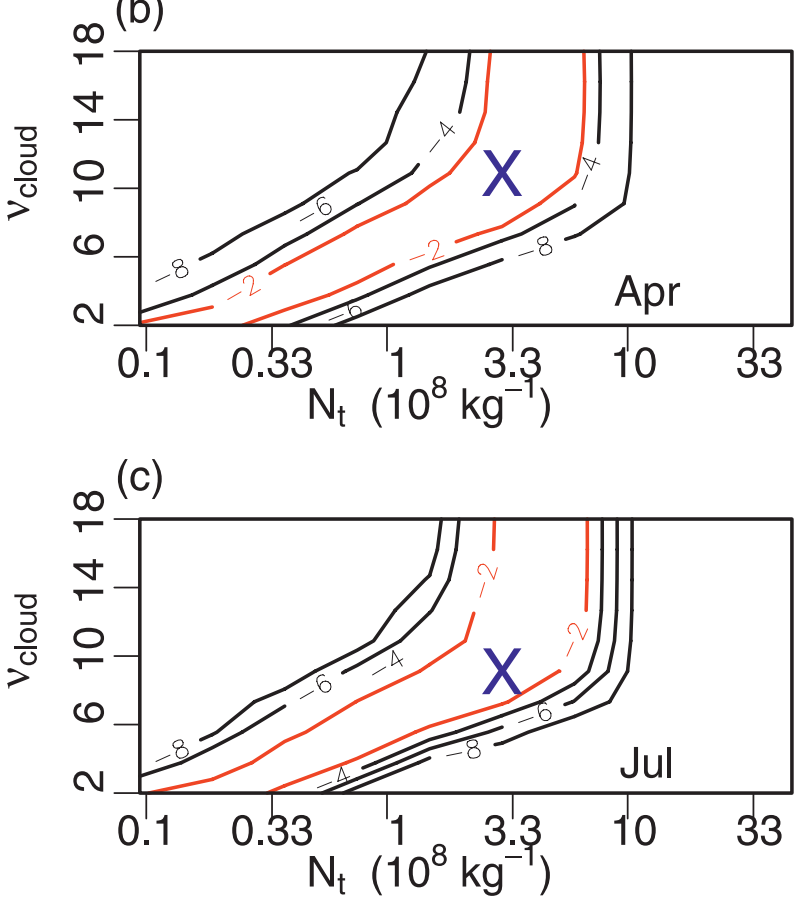

FIG. 2. As in Fig. 1a, but for simulations that were carried out for (a) January 2002, (b) April 2001, and (c) July 2001.

month of a multiyear simulation. However, if model parameters were specific to smaller, subcontinental areas, they would likely have increased seasonality.

Another way to test the seasonality of parameter values is to return to the October optimization, but to regionalize the datasets in alternate ways. We constructed likelihood functions based exclusively on Northern Hemisphere data, Southern Hemisphere data, midlatitudes only (in each hemisphere and separately), and tropics only. In each case, we found that the maximum likelihood parameters fell within the $95 \%$ c.l. region shown in Fig. 1a.

\section{d. Parameter values and model resolution}

Because the horizontal CLS of OLAM's unstructured grid mesh is readily modified by the user it is important (a)

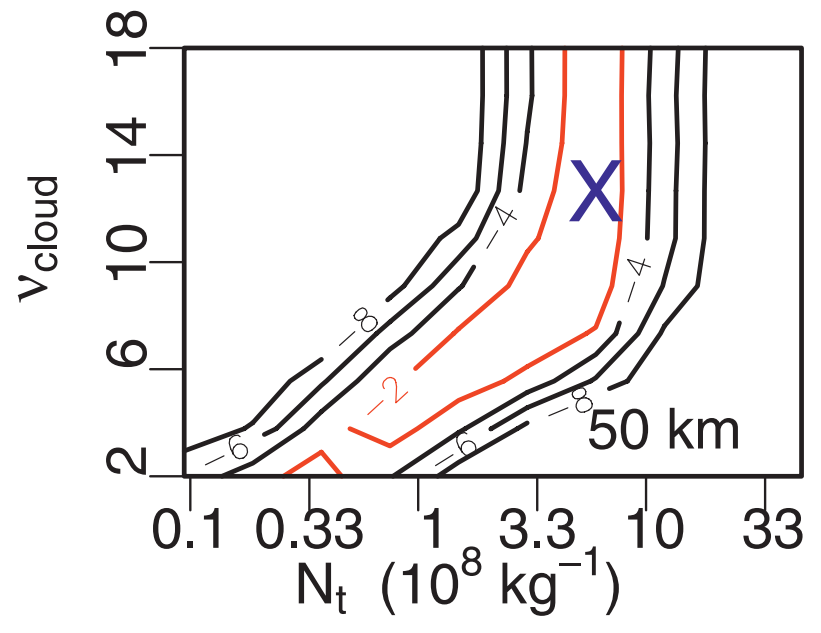

(b)

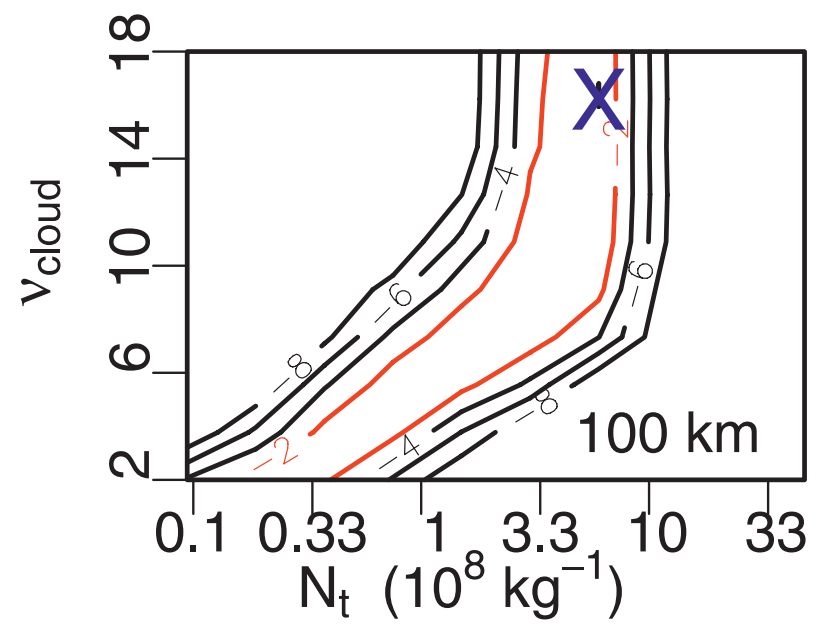

FIG. 3. As in Fig. 1a, but for simulations that were carried out for (a) 50- and (b) 100-km CLS.

to evaluate model performance for different CLSs. Two further optimizations were carried out using global CLSs of 100 and $50 \mathrm{~km}$ (Table 1; Fig. 3). The likelihood function contours (with all datasets weighted equally) are similar to those obtained from the 200-km CLS optimization, exhibiting strong $N_{t}-\nu_{\text {cloud }}$ covariance at small $N_{t}$. One difference of these smaller-CLS runs is an increase in the optimum $N_{t}$ from $3 \times 10^{8} \mathrm{~kg}^{-1}$ to $6 \times$ $10^{8} \mathrm{~kg}^{-1}$ and an increase in optimum $\nu_{\text {cloud }}$ from 9 to 16 (100-km CLS) or 12 (50-km CLS). However, the optimal parameters from the 200-km CLS optimization lie within the $95 \%$ c.l. region of the smaller-CLS optimizations. We will investigate the biases incurred by running a high-resolution simulation with parameters obtained from a lower-resolution optimization in section 6 a. 


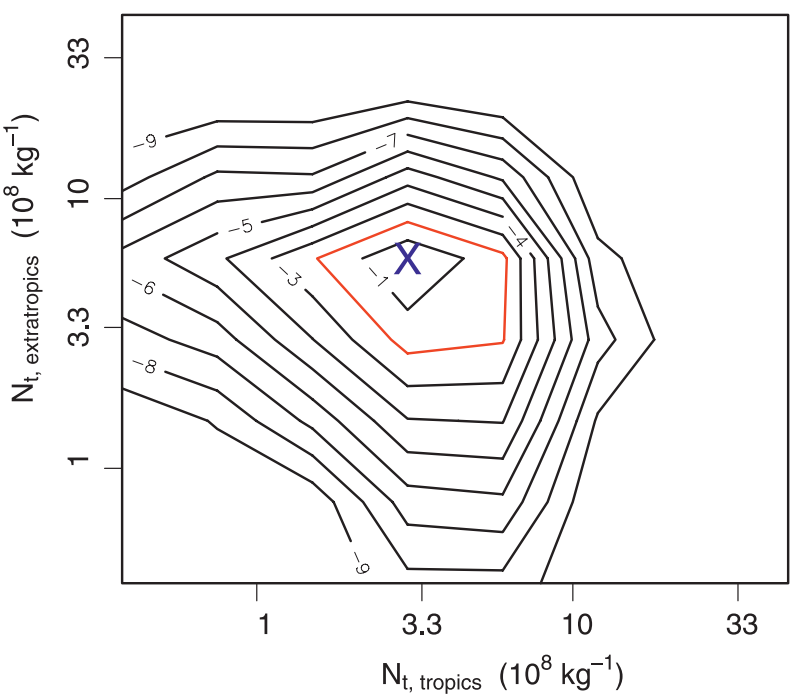

FIG. 4. Maximum likelihood contours for the PO7 optimization.

\section{e. Optimization of other parameters}

A different optimal $N_{t}$, but nearly identical $\nu_{\text {cloud }}$, resulted for likelihood functions defined solely in terms of tropical fluxes compared to likelihood functions defined solely in terms of temperate fluxes. This motivated two further optimizations: first, we used separate $N_{t}$ values for tropics (latitude between $20^{\circ} \mathrm{S}$ and $20^{\circ} \mathrm{N}$ ) and extratropics (everything else); second, we used different $N_{t}$ values for land and sea. Both optimizations used a fixed $\nu_{\text {cloud }}$ of 9, CLS of $200 \mathrm{~km}$, and ran for October 2001. The optimization of tropical and extratropical $N_{t}$ found a larger optimal $N_{t}$ value for the extratropics (Fig. 4); however, a globally constant value of about $3 \times$ $10^{8} \mathrm{~kg}^{-1}$ fell within the uncertainty interval. Similarly, optimization failed to decisively distinguish between separate land and sea values for $N_{t}$.

We experimented with optimizing other parameters, including the characteristic diameters of other hydrometeors; shape parameters of other hydrometeors; and two parameters from the cumulus scheme: the dissipation time scale and the lifting depth threshold for triggering convection (i.e., distance between level of free convection and the lowest level with updrafts). However, modification of these parameters did not change the overall likelihood score by more than 1 log-likelihood unit. Of these additional parameters, the lifting depth threshold had the largest effect on likelihood, obtaining an optimal value of about $50 \mathrm{mb}$.

\section{Model evaluation}

\section{a. Impact of parameter values on simulated fluxes}

Five simulations from section 5 were selected to illustrate how microphysics parameters affected OLAM's ability to simulate radiation and precipitation. The first two correspond to PO1 and PO6 (Table 1), using optimal parameter values; these allow us to evaluate the quality of the optimized model's fluxes at 200- and 50-km CLS. The third corresponds to using optimal values in configuration $\mathrm{PO} 7$, which illustrates the improvement deriving from allowing tropical and temperate values of $N_{t}$. The fourth used the optimal parameters from PO1 but the grid configuration of PO6. This run (subsequently called "PO6 swap") gives information on possible systematic biases when the model's configuration does not exactly correspond to one of the optimizations reported here. The fifth simulation (P-RAMS) used the PO1 grid configuration together with the standard microphysics parameters of RAMS $\left(N_{t}=3 \times 10^{8} \mathrm{~kg}^{-1} ; \nu_{\text {cloud }}=5\right)$. Table 2 shows global-average biases and gridcell-based RMS errors for DSFC shortwave, UTOA shortwave, DSFC longwave, UTOA longwave, and precipitation. Almost all biases were statistically significant at the $95 \%$ c.l. All simulations overestimate DSFC shortwave between $50^{\circ}$ and $70^{\circ} \mathrm{S}$, a region that is substantially overlapping with the baroclinic storm tracks (Fig. 5a). The higher-resolution PO6 leads to a similar bias but slightly lower RMS error than PO1. PO6-swap tends to overestimate in Southern Hemisphere midlatitudes, and PO7 underestimates in the tropics. P-RAMS has an RMS error about $50 \%$ larger than the other simulations.

Two ways to address the remaining mismatch include location-specific microphysical parameters that account for the unique controls on Southern Ocean CCN concentrations (Vallina et al. 2006), and moving to even finer resolution. Finer resolution would both allow better resolution of updrafts, and also enhance the model's ability to capture the spatial variations in meridional velocity and geopotential height associated with regional cyclone formation (Simmonds and Keay 2000).

UTOA shortwave fluxes are shown in Fig. 5b. Similar to the case of DSFC shortwave, large errors occur in the $50^{\circ}-60^{\circ} \mathrm{S}$ latitude band for most simulations. However, $60^{\circ}-70^{\circ} \mathrm{S}$ is better simulated here, suggesting that surface albedo is probably overestimated to compensate for the overestimated DSFC shortwave. Such albedo errors could have easily occurred in the simulation because sea ice albedo is fixed instead of exhibiting variation with snow cover. Overall, PO6 has the smallest RMS error (but PO1 has a similar bias), and P-RAMS is an outlier, having both the largest bias and RMS error. Differences in longwave radiation are far less pronounced. For DSFC longwave (Fig. 6a), the PO7 simulation has both the smallest bias and RMS error (Table 2). All simulations overestimate UTOA longwave radiation (Fig. 6b). The degree of globalaverage overestimation varies slightly, with biases ranging from $2.9 \%$ in $\mathrm{PO} 7$ to $3.8 \%$ in PO6-swap. 


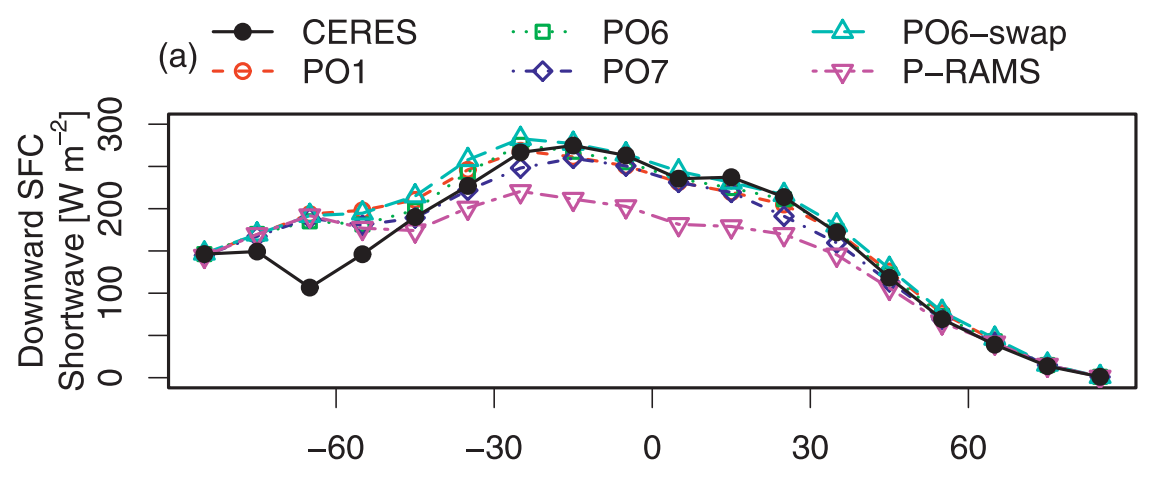

(b)

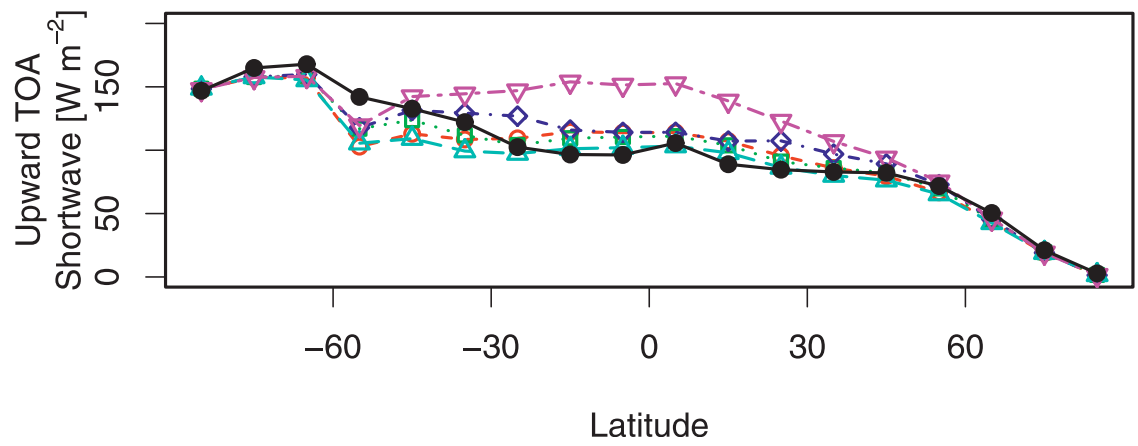

FIG. 5. Zonal average shortwave fluxes for October 2001 for selected optimizations. (a) DSFC and (b) UTOA shortwave.

Simulated precipitation is compared to GPCP in Fig. 7. On the global average, the PO6 simulation has the smallest bias and RMS error (Table 2). While GPCP has a clearly defined maximum between $0^{\circ}$ and $10^{\circ} \mathrm{N}$, the PO6 simulation yields tropical precipitation that is more spatially spread out, especially to the south. The simulated underestimate between $0^{\circ}$ and $10^{\circ} \mathrm{N}$ occurs mainly over the oceans, especially the Atlantic (section 6b); the overestimate between $10^{\circ}$ and $20^{\circ} \mathrm{S}$ is over both the oceans and Africa. Extratropical storm tracks are underestimated, more prominently in the Southern Hemisphere as might be expected from the shortwave biases (Fig. 5). Overall, these results suggest that further model improvement would result from an improved parameterization of tropical convection, possibly with more finely resolved sea surface temperatures; a better representation of sea ice albedo; and an improved representation of cloud processes particular to the Southern Ocean.

The most prominent differences between PO1 and PO6 occur in the extratropical storm tracks, where PO1 more strongly underestimates precipitation. Also in this region, the performance of simulation PO6-swap

TABLE 2. Global-average biases and gridcell-based RMS errors for DSFC shortwave, UTOA shortwave, DSFC longwave, UTOA longwave, and precipitation. Radiation units are $\mathrm{W} \mathrm{m} \mathrm{m}^{-2}$ and precipitation units are $\mathrm{mm} \mathrm{month}^{-1}$. Biases not statistically significant at the $95 \%$ c.l. are in bold.

\begin{tabular}{|c|c|c|c|c|c|}
\hline Flux & PO1 & PO7 & PO6 & PO6-swap & P-RAMS \\
\hline DSFC shortwave, bias & 4.0 & -4.5 & 4.1 & 12 & -29 \\
\hline DSFC shortwave, RMSE & 38 & 39 & 35 & 36 & 59 \\
\hline UTOA shortwave, bias & 1.3 & 8.7 & 1.5 & -5.6 & 27 \\
\hline UTOA shortwave, RMSE & 28 & 30 & 24 & 25 & 47 \\
\hline DSFC longwave, bias & -3.3 & 2.0 & -6.0 & -12 & 4.6 \\
\hline DSFC longwave, RMSE & 22 & 22 & 22 & 24 & 23 \\
\hline UTOA longwave, bias & 13 & 10 & 10 & 13 & 12 \\
\hline UTOA longwave, RMSE & 21 & 19 & 20 & 22 & 20 \\
\hline Precipitation, bias & -2.1 & -1.2 & 0.36 & -0.93 & -1.2 \\
\hline Precipitation, RMSE & 84 & 83 & 80 & 83 & 81 \\
\hline
\end{tabular}




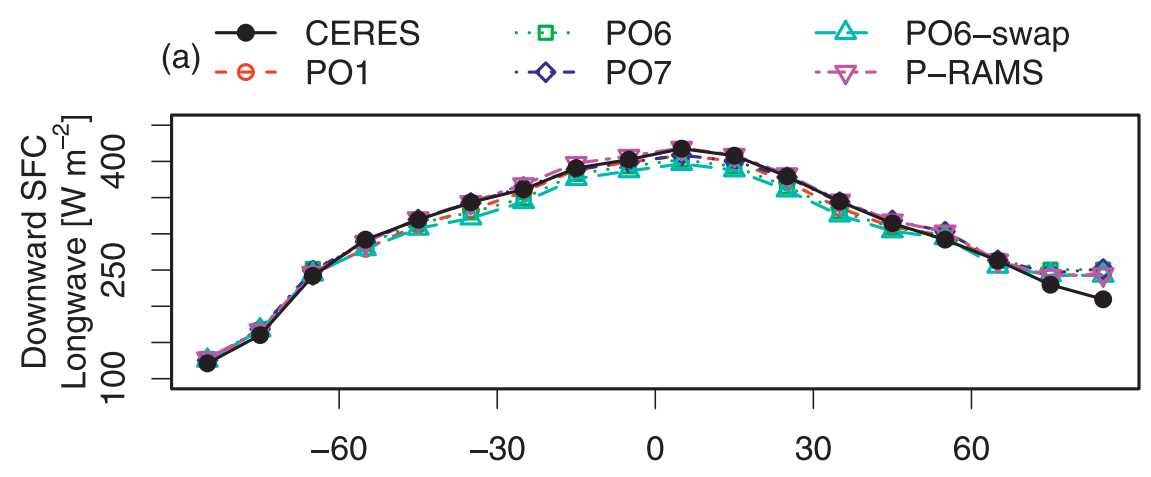

(b)

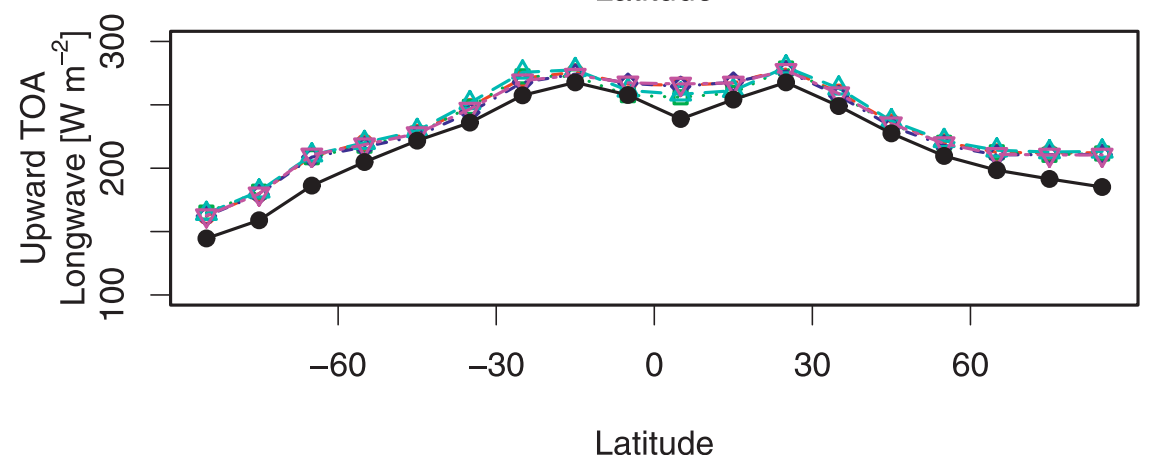

FIG. 6. As in fig. 5, but for longwave fluxes.

is intermediate between PO6 and PO1. These results indicate that global biases may be increased by a few percent when simulations are carried out with parameters taken from an optimization having a different model configuration. We were surprised to see the relatively small impact of allowing tropical and extratropical $N_{t}$ values (PO7), though this will be discussed further in section $6 \mathrm{~b}$.

Collectively, these simulations gave different amounts of radiation and precipitation both because of changes in total cloud water mass and changes in the size distribution of cloud droplets. For each $10^{\circ}$ latitude band within each simulation, we carried out linear fits between cloud water masses and (i) precipitation and (ii) each radiative flux. Fits that were statistically significant at the $95 \%$ confidence level are shown in Table 3. In general, total cloud water was a good predictor for precipitation in midlatitudes. Its impact was less in the tropics, where most of the precipitation is generated by the cumulus parameterization; this parameterization operates by immediately precipitating any water that condenses as a result of convective readjustment. In contrast, cloud water mass was a good predictor for each of the radiative fluxes in the tropics and at very high latitudes. This result implies that the shape of the cloud droplet size distribution is important for determining radiation in midlatitudes.

\section{b. Model performance on decadal time scales}

Model performance on monthly time scales does not necessarily indicate performance on longer time scales; not only is it possible that the optimization parameters vary on such scales, but model errors may accumulate, causing the simulation to drift into an unrealistic state.

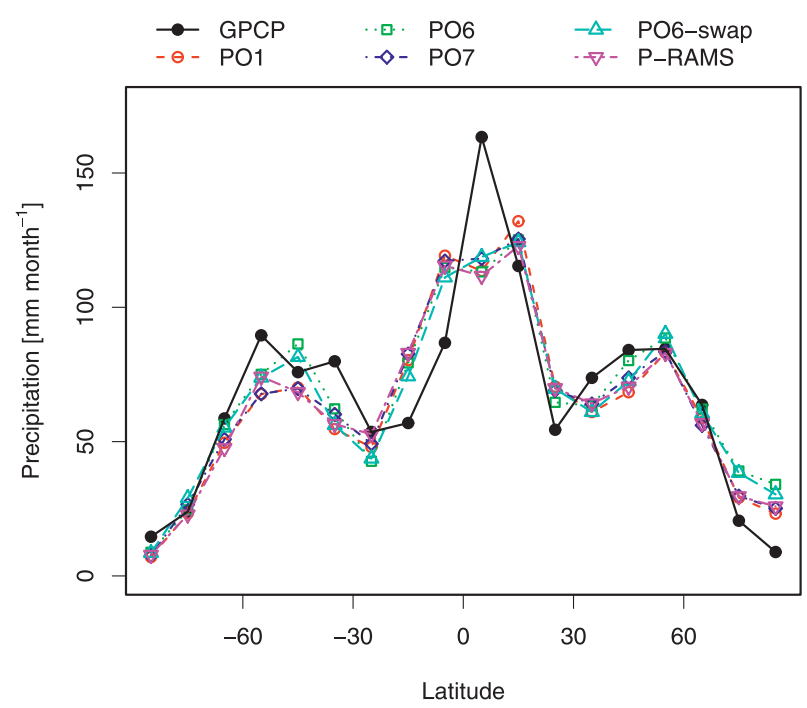

FIG. 7. Zonal average precipitation for October 2001 for selected optimizations. 
TABLE 3. Latitudes where fits between total cloud water mass (TCW) and shortwave radiation, longwave radiation, and precipitation were significant at the $95 \%$ c.l.

\begin{tabular}{ll}
\hline \hline \multicolumn{1}{c}{ Flux } & \multicolumn{1}{c}{ Latitude bins } \\
\hline Precipitation-TCW & $70^{\circ}-60^{\circ} \mathrm{S}, 50^{\circ}-30 \mathrm{~S}, 20^{\circ} \mathrm{S}-0,30^{\circ}-90^{\circ} \mathrm{N}$ \\
DSFC shortwave-TCW & $70^{\circ}-60^{\circ} \mathrm{S}, 0^{\circ}-30^{\circ} \mathrm{N}, 80^{\circ}-90^{\circ} \mathrm{N}$ \\
UTOA shortwave-TCW & $90^{\circ}-80^{\circ} \mathrm{S}, 0^{\circ}-30^{\circ} \mathrm{N}, 70^{\circ}-90^{\circ} \mathrm{N}$ \\
DSFC longwave-TCW & $20^{\circ} \mathrm{S}-30^{\circ} \mathrm{N}, 70^{\circ}-80^{\circ} \mathrm{N}$ \\
UTOA longwave-TCW & $80^{\circ}-70^{\circ} \mathrm{S}, 30^{\circ}-20^{\circ} \mathrm{S}, 10^{\circ} \mathrm{S}-0^{\circ}, 20^{\circ}-40^{\circ} \mathrm{N}$ \\
\hline
\end{tabular}

We therefore tested OLAM by simulating a $10-y r$ period, October 1996-September 2006, and comparing the results to CERES (March 2000-October 2005; the period for which data were available) and GPCP (October 1996-September 2006). We consider simulations carried out at 100-km CLS, 200-km CLS, and variable resolution (100-200-km CLS).

\section{1) Simulation at 100-KM CLS}

Figure 8a shows a time series of the monthly-average DSFC shortwave radiation. Temperate radiation is well simulated with typical biases of less than $3 \mathrm{~W} \mathrm{~m}^{-2}$; however, tropical radiation has a systematic low bias of about $19 \mathrm{~W} \mathrm{~m}^{-2}$. Polar regions are overestimated from November to January with biases of about $50 \mathrm{~W} \mathrm{~m}^{-2}$, but are much better simulated during other months with biases typically less than $5 \mathrm{~W} \mathrm{~m}^{-2}$. Because CERES has relatively large uncertainties at high latitudes, it is difficult to say whether the model needs improvement here.

Corresponding time series for gridcell-based RMS errors followed similar patterns; monthly RMS errors ranged between 75 and $85 \mathrm{~W} \mathrm{~m}^{-2}$ for all regions. Biases were statistically significant at the $95 \%$ c.l. in most months (Table 4). Maps of decadal mean DSFC shortwave, shown in Fig. 8b (OLAM) and Fig. 8c (CERES), illustrate the model's ability to simulate smaller-scale radiative fluxes. While the average bias in the tropics is relatively small, tropical land is overestimated and tropical ocean is underestimated. Temperate biases are generally smaller, but temperate land is slightly overestimated. The model underestimates in Antarctica, but there the uncertainty in the data is relatively large. This pattern of biases also helps to explain why optimizations with different $N_{t}$ for land and sea failed to yield improvements: if DSFC shortwave were increased over oceans, tropical oceans would improve but temperate oceans would become worse. This suggests that three values of $N_{t}$ (tropical and temperate oceans, and land) may need to be optimized with a global $\nu_{\text {cloud }}$ value. However, such four-parameter optimizations are beyond the scope of this study because of limited computing resources.
Figure $8 \mathrm{~b}$ indicates that two-gridcell interval noise is present in OLAM simulations, even in decadal averages. This noise is a by-product of using a triangular mesh, ultimately arising from the fact that any given triangle directly exchanges information with only a subset of the triangles with which it shares a vertex. This problem can be corrected either by implementing a second-order upwinding procedure in the advection algorithm, or by replacing the triangular grid mesh with a hexagonal mesh. We are currently carrying out the implementation of both solutions and will report their effects on model performance in a future publication.

Time series of monthly UTOA shortwave radiation is shown in Fig. 9a. Global biases, ranging from 0 to $-5 \mathrm{~W} \mathrm{~m}^{-2}$, have the opposite sign of DSFC shortwave biases. Here, tropical areas have a systematic positive bias and polar areas have a negative bias from October to February. RMS errors are typically $45 \mathrm{~W} \mathrm{~m}^{-2}$, but reach $75 \mathrm{~W} \mathrm{~m}^{-2}$ during December-February (DJF) in polar regions. Biases were typically statistically significant (Table 4). Comparing the decadal average maps (Fig. 9b for OLAM and Fig. 9c for CERES), it is evident that the model underestimates UTOA shortwave for the Southern Ocean and Antarctica; in contrast, radiation in the Arctic is better simulated. In the tropics, there are compensating biases between land areas (negative bias) and oceans (positive bias).

DSFC longwave is simulated in temperate regions with statistically significant (Table 4) negative biases of $5 \mathrm{~W} \mathrm{~m}^{-2}$ and RMS errors of about $195 \mathrm{~W} \mathrm{~m}^{-2}$ (Fig. 10a). Corresponding tropical biases are similar, but RMS errors reached $215 \mathrm{~W} \mathrm{~m}^{-2}$; especially in DJF, many of the biases are not statistically significant. These discrepancies can perhaps be resolved by incorporating a partial cloudiness scheme (section 7), which would improve the representation of cumulus clouds in 100-km CLS simulations. Biases in polar regions are seasonal, with the model underestimating most strongly in the Northern Hemisphere summer. In particular, the model does not reproduce the CERES's peaks in polar longwave during May-June. Maps of the decadal-average flux, shown in Fig. 10b for OLAM and Fig. 10c for CERES, indicate that the underestimation in the tropics occurs mainly over land, providing additional evidence that the model is not generating sufficient cloudiness for those grid cells. In mountainous areas such as the Himalayas and Andes, both model and data agree in having less longwave than zonal mean.

Upward TOA longwave is systematically simulated with a statistically significant (Table 4) positive bias in temperate and tropical regions (Fig. 11a), where RMS errors are typically $160 \mathrm{~W} \mathrm{~m}^{-2}$. While there is little overall bias in polar regions, the model does not capture 


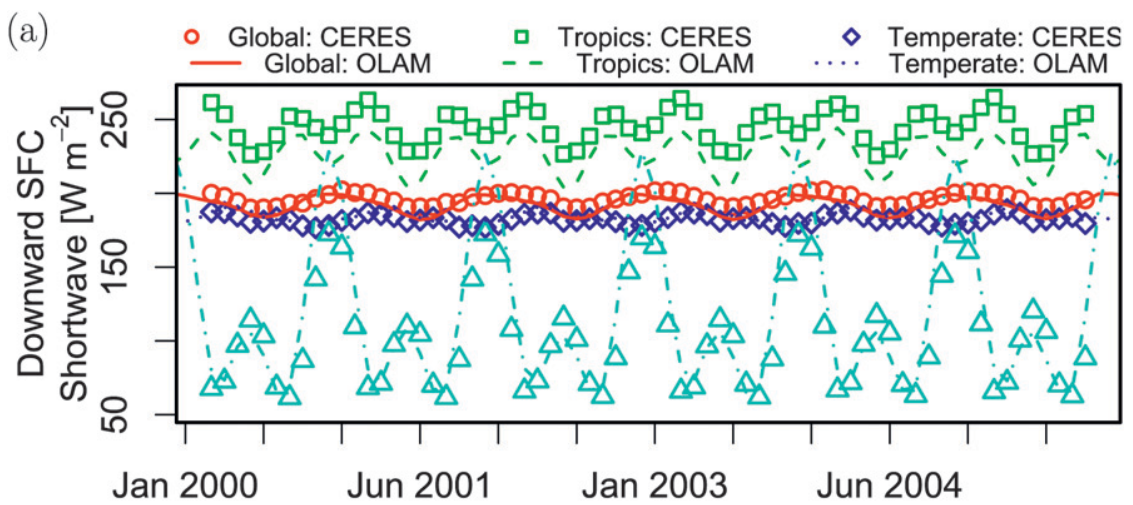

(b)

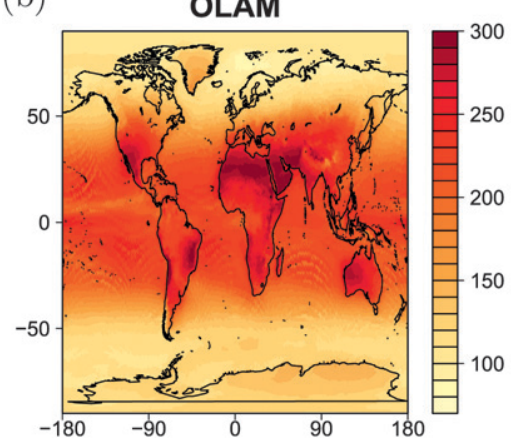

(c)

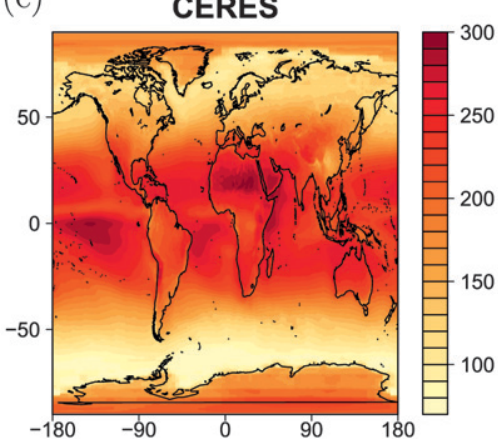

FIG. 8. DSFC shortwave from the decadal 100-km CLS simulation. (a) Time series of monthly mean fluxes. (b) Map of the simulated time-average (March 2000-October 2005) flux. (c) Map of time-average (March 2000-October 2005) CERES flux. Units are $\mathrm{W} \mathrm{m}^{-2}$.

the bimodal seasonality in the CERES data (Table 4). Polar RMS errors ranged from $125 \mathrm{~W} \mathrm{~m}^{-2}$ in JuneAugust (JJA) to $150 \mathrm{~W} \mathrm{~m}^{-2}$ in DJF. Maps of the decadal average longwave are shown in Fig. 11b for OLAM and Fig. 11c for CERES. Over land, the existence of a positive bias is not surprising; if cloudiness is underestimated, relatively more of the land surface is exposed, allowing more longwave to escape into space. Over ocean, the model captures the pattern of variability, but exhibits a positive bias. The relative uniformity of the bias suggests that the simulated interaction of the radiation scheme with well-mixed absorbers (e.g., $\mathrm{CO}_{2}, \mathrm{CH}_{4}, \mathrm{~N}_{2} \mathrm{O}$, and halocarbons) may need to be improved. We are currently incorporating a more sophisticated radiation scheme into OLAM to test this hypothesis.

OLAM's estimates for monthly precipitation are compared to GPCP in Fig. 12. Tropical precipitation has a systematic bias of about $13 \mathrm{~mm}$ month $^{-1}$, while temperate and polar precipitation biases are less than $2 \mathrm{~mm}$ month $^{-1}$. These biases are statistically significant in most months (Table 4). The RMS error is also larger in the tropics $\left(140 \mathrm{~mm} \mathrm{month}^{-1}\right)$ than in either temperate $\left(70 \mathrm{~mm}\right.$ month $\left.{ }^{-1}\right)$ or polar $\left(30 \mathrm{~mm} \mathrm{month}^{-1}\right)$ regions. However, in the tropics, the sparseness of the rain gauge network contributes to uncertainty in the GPCP data, and thus it is not clear whether it is actually closer than

TABLE 4. Proportion of months (\%) with statistically significant biases at $95 \%$ c.l. for the $10-\mathrm{yr} 100-\mathrm{km}$ CLS simulation.

\begin{tabular}{lrrrr}
\hline \multicolumn{1}{c}{ Flux } & DJF & MAM & JJA & SON \\
\hline DSFC shortwave-tropical & 100 & 100 & 100 & 100 \\
DSFC shortwave-temperate & 87 & 89 & 100 & 94 \\
DSFC shortwave-polar & 100 & 67 & 94 & 100 \\
UTOA shortwave-tropical & 100 & 100 & 100 & 100 \\
UTOA shortwave-temperate & 73 & 89 & 83 & 94 \\
UTOA shortwave-polar & 100 & 100 & 100 & 100 \\
DSFC longwave-tropical & 47 & 89 & 89 & 94 \\
DSFC longwave-temperate & 80 & 72 & 100 & 94 \\
DSFC longwave-polar & 87 & 67 & 78 & 65 \\
UTOA longwave-tropical & 100 & 100 & 100 & 100 \\
UTOA longwave-temperate & 100 & 100 & 100 & 100 \\
UTOA longwave-polar & 67 & 72 & 100 & 82 \\
Precipitation-tropical & 97 & 100 & 100 & 100 \\
Precipitation-temperate & 97 & 93 & 97 & 90 \\
Precipitation-polar & 87 & 93 & 70 & 80 \\
\hline
\end{tabular}



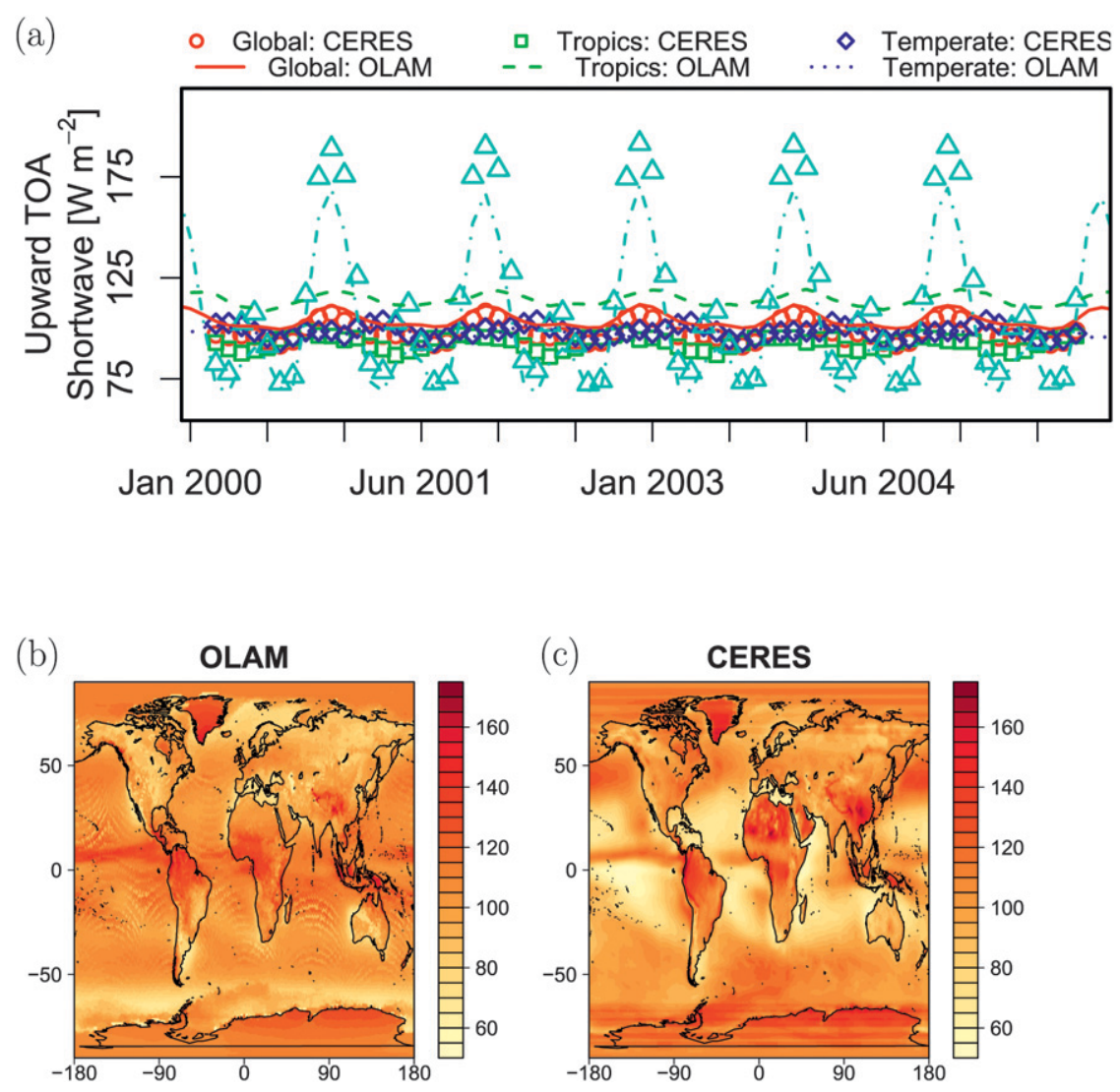

FIG. 9. As in Fig. 8, but for UTOA shortwave.

OLAM to reality. In the Amazon (defined to lie within $15^{\circ} \mathrm{S}-0^{\circ}$ latitude and $75^{\circ}-49^{\circ} \mathrm{W}$ longitude), for example, the average GPCP precipitation is $2110 \mathrm{~mm} \mathrm{yr}^{-1}$, markedly less than the $\sim 2500 \mathrm{~mm} \mathrm{yr}^{-1}$ estimated by Richey et al. (1991). The OLAM precipitation estimate for this region is intermediate, $2408 \mathrm{~mm} \mathrm{yr}^{-1}$.

Decadal average maps (Fig. 13a for OLAM and Fig. 13b for GPCP) indicate that the model simulates the Pacific ITCZ and the South Indian Ocean ITCZ with approximately the correct position and intensity. The South Pacific convergence zone is simulated by the model, but does not extend as far southeast as in GPCP. The South Atlantic convergence zone is also simulated, but is too weak over southeast Brazil. The Atlantic ITCZ is present in the simulation, but is weaker than observed. OLAM also simulates a precipitation maximum near Bangladesh; however, its spatial extent is overstated by the model. This problem is likely related to the proximity of the Himalayas, which are not fully resolved at 100-km CLS. Temperate zone storm tracks in the Northern Atlantic and Pacific are evident in the model, but are underestimated. Overall, these results suggest that further model improvement would result from an improved parameterization of tropical convection, possibly with more finely resolved sea surface temperatures and a separate parameterization for shallow convection.

The global radiation and precipitation biases generated by OLAM are similar to those obtained from these more established models (cf. Figs. 15e and $17 \mathrm{~g}$ of Delworth et al. 2006), but spatial patterns of biases exhibit both similarities and differences. In terms of UTOA shortwave, both OLAM and GFDL AM2.1 exhibit negative biases over the Southern Ocean and positive biases over the subtropical Atlantic and Pacific Oceans. However, over midlatitude land areas, OLAM and GFDL give biases of the opposite sign. Both models underestimate precipitation in the Atlantic ITCZ, but OLAM simulates more precipitation in the Amazon.

\section{2) 200-KM CLS AND VARIABLE RESOLUTION SIMULATIONS}

Radiation maps and time series from both the 200-km CLS and the variable-resolution simulations (not shown) are very similar to their $100-\mathrm{km}$ CLS counterparts. However, the precipitation fields of all simulations differ markedly from each other. Decadal average maps are shown in Fig. 13c for the 200-km CLS simulation and 


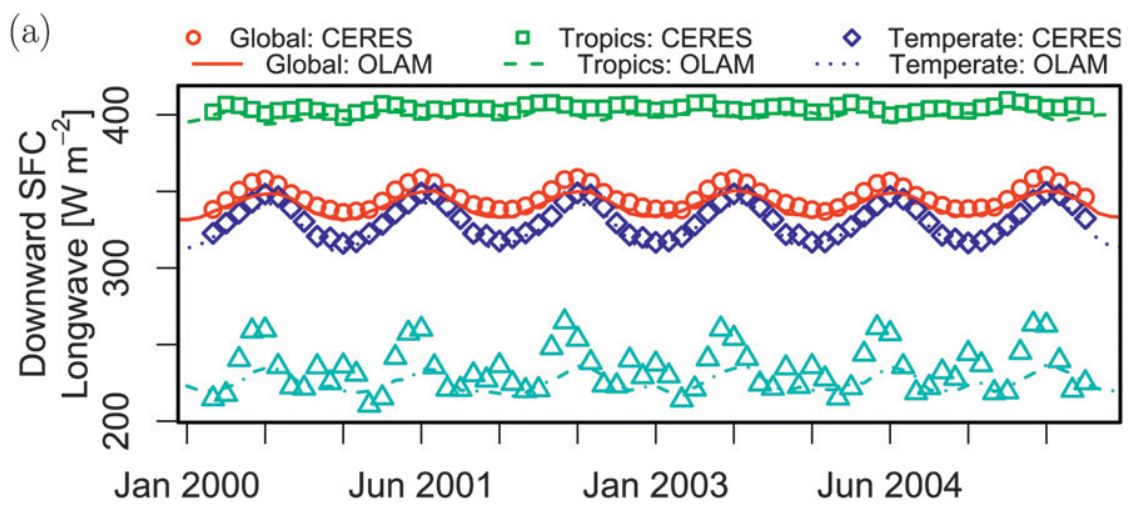

(b)

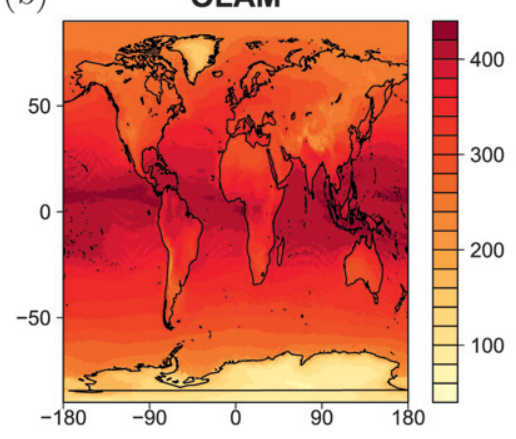

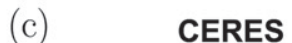

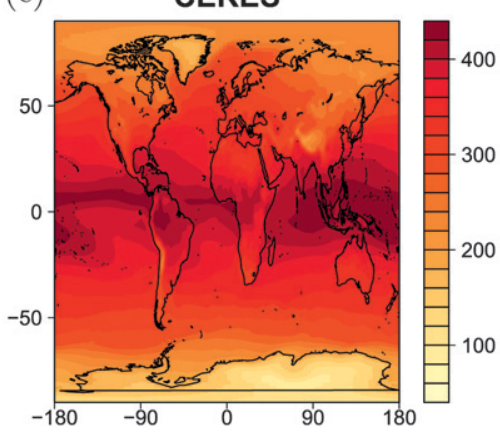

FIG. 10. As in Fig. 8, but for DSFC longwave.

Fig. $13 \mathrm{~d}$ in the variable-resolution simulation. Three differences between the 100-km CLS (Fig. 13a) and 200-km CLS simulations stand out. First, the small-scale grid cell noise is more pronounced in the 200-km CLS simulation (see especially the western Pacific and the Indian Oceans). Preliminary tests indicate that this mode can be entirely eliminated when a hexagonal grid mesh is used. Second, the ITCZ is less well defined in the 200-km CLS simulation; this is unsurprising given the ITCZ's narrow latitudinal width. Finally, the Amazon is not nearly as well simulated in the 200-km CLS simulation, which gives an average precipitation of only $1931 \mathrm{~mm} \mathrm{yr}^{-1}$ - a $20 \%$ reduction from the $100-\mathrm{km}$ CLS simulation.

Problems in the Amazon are likely to be due to the coarse representation of topography at 200-km CLS. Earlier work demonstrated that simulating the Andes Mountains at $100-\mathrm{km}$ CLS or finer improved simulations of the Amazon hydroclimate (Medvigy et al. 2008). Essentially, the coarsely represented mountains are too low to prevent relatively cool, dry air from blowing into South America from the eastern Pacific during times of neutral Pacific sea surface temperatures. This results in a cooling and drying of the Amazon.
Reducing the bias in the Amazon comes at a steep computational cost because running a simulation at $100-\mathrm{km}$ CLS is approximately 4 times slower than running a simulation at 200-km CLS (using the same time step). However, OLAM offers an alternative: use of a variable-resolution grid mesh. We therefore ran a third simulation for which the CLS was $100 \mathrm{~km}$ over much of South America and nearby oceans, gradually coarsening to $200 \mathrm{~km}$ for the rest of the globe (Fig. 13d). The computational cost of the variable resolution grid was 1.7 times the cost of the $200-\mathrm{km}$ CLS grid. The resulting precipitation over the Amazon is within 1\% of the value obtained in the 100-km CLS simulation. Meanwhile, the rest of the world's simulated precipitation is similar to that of the run with $200-\mathrm{km}$ CLS. Thus, we conclude that OLAM's variable-resolution capability successfully corrects the dry Amazon problem at a relatively modest computational cost.

\section{Summary and conclusions}

This work builds on the results of Walko and Avissar (2008a,b), here illustrating the capability of the OceanLand-Atmosphere Model (OLAM) to realistically 


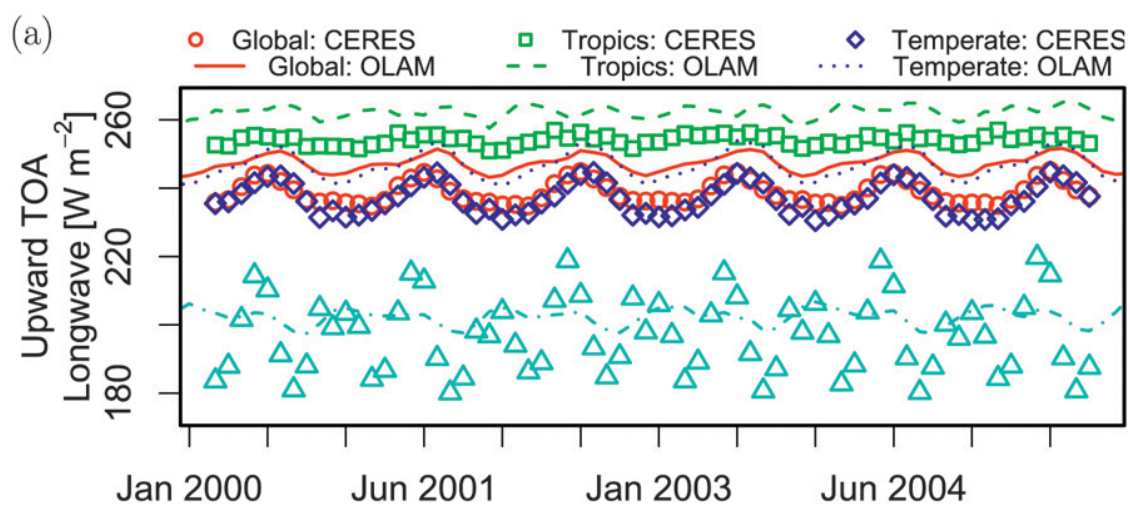

(b)

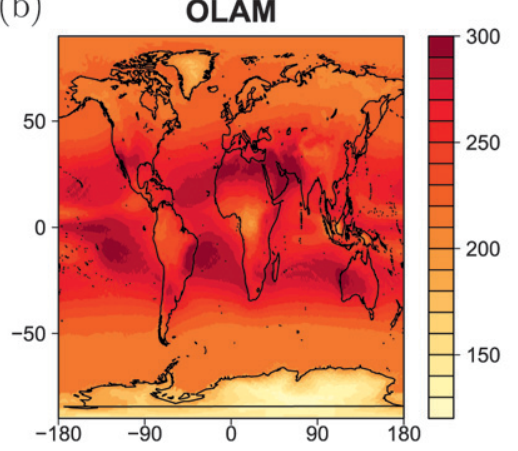

(c)

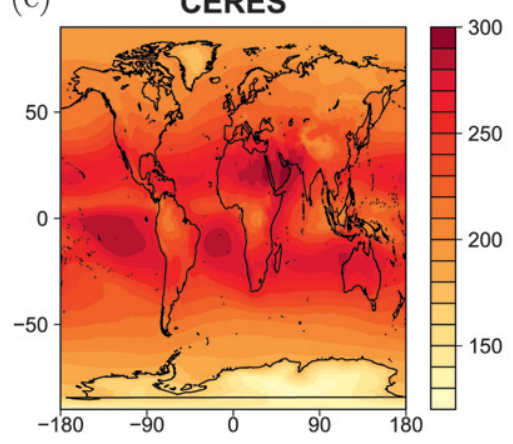

FIG. 11. As in Fig. 8, but for UTOA longwave.

represent radiation and precipitation on monthly to decadal time scales. As with other GCMs (Murphy et al. 2004; Stainforth et al. 2005), it was necessary to adjust empirical parameters in order to predict a realistic global radiation balance. However, unlike many other of stateof-the-art climate models (Collins et al. 2006; Delworth et al. 2006), we here carried out an objective, maximumlikelihood optimization to ensure that optimal parameters

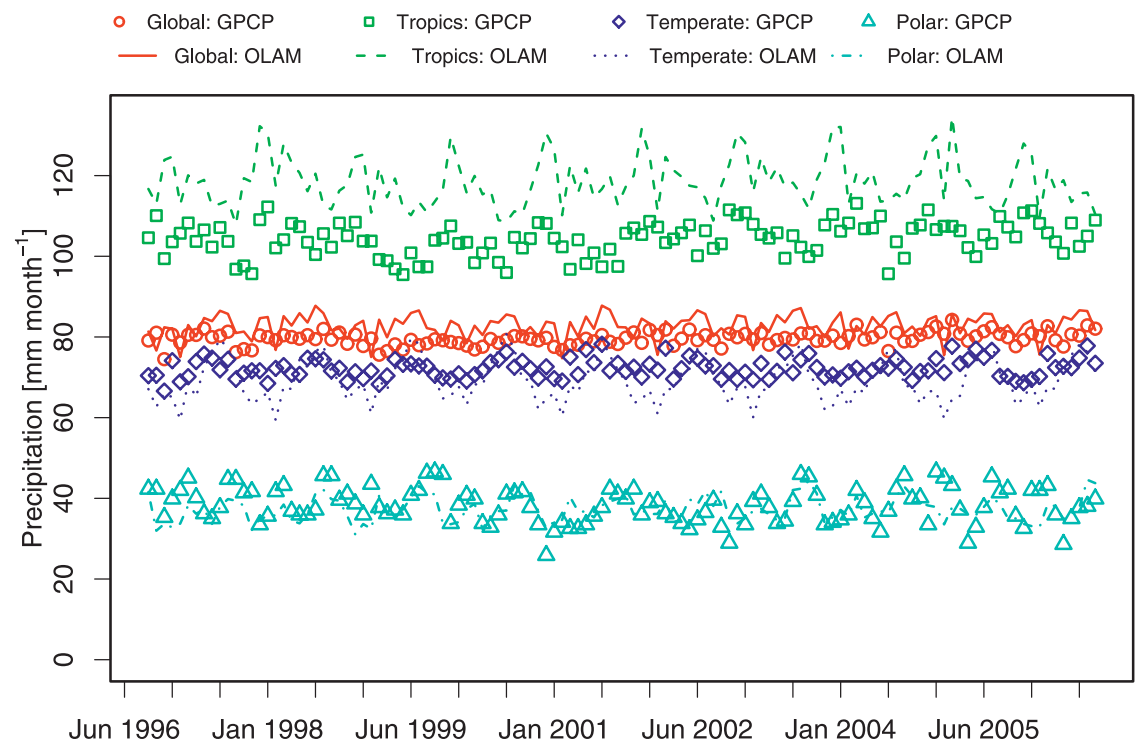

FIG. 12. Time series of monthly-mean precipitation from the 100-km CLS simulation. 
(a) OLAM, $100 \mathrm{~km}$

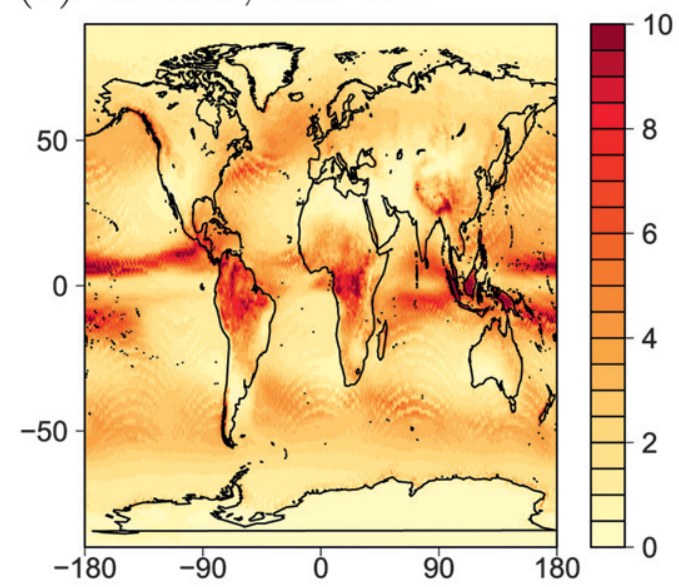

(c) OLAM, $200 \mathrm{~km}$

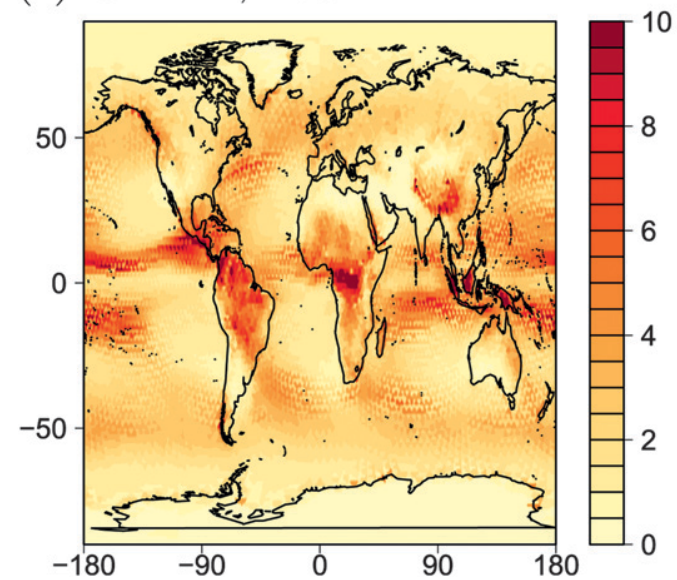

(b) GPCP

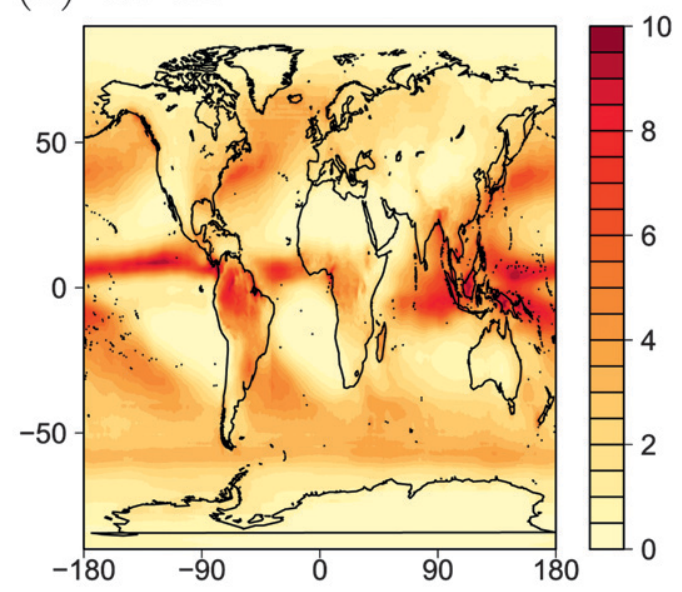

(d) OLAM, 100-200 km

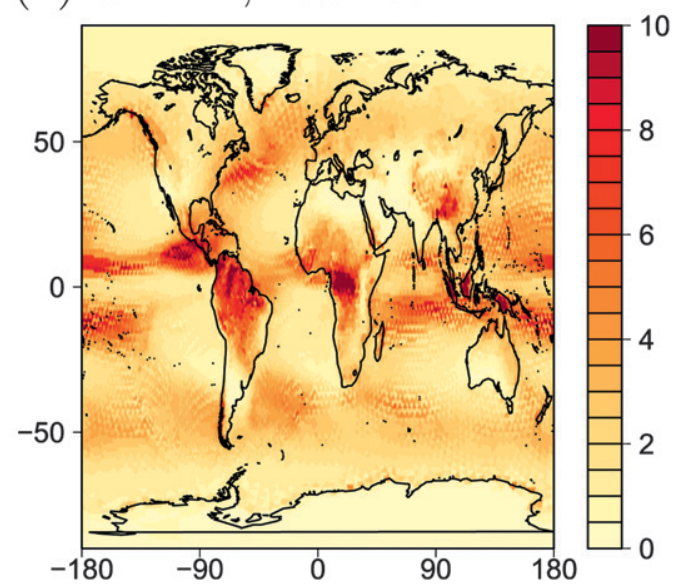

FIG. 13. Map of time-average precipitation from October 1996-September 2006. (a) OLAM 100-km CLS simulation, (b) GPCP, (c) OLAM 200-km CLS simulation, and (d) OLAM variable resolution simulation. South America and the nearby ocean were simulated at 100-km CLS; the rest of the world was simulated at 200-km CLS. Units are mm day ${ }^{-1}$.

and their uncertainties were retrieved. We found that parameters specifying cloud properties were much more strongly constrained than parameters specifying the properties of other hydrometeors.

The optimized parameter values pass two important self-consistency checks. First, as shown in Fig. 1, independent datasets agree as to what constitutes a "good" parameter set. Second, there are no significant largescale biases in radiation or precipitation when a decadal integration was done with parameters gleaned from a 1-month optimization (Figs. 8-13). This is a powerful result; previously, computational limits and a perceived need to optimize with multiyear datasets have allowed only highly simplified GCMs to be objectively optimized (Jones et al. 2005; Severigns and Hazeleger 2005).

Furthermore, this realistic decadal performance suggests that any compensating errors possibly incurred at the expense of the optimizing radiation and precipitation have been minimal. If, for example, optimization caused unrealistic liquid cloud water mixing ratios, these errors would almost certainly feed back into longwave radiation and precipitation, and alter the atmospheric energy balance. However, no such transient was seen.

Our study also indicates that the precipitation climatology differs between the optimal model at $200-\mathrm{km}$ CLS and the optimal model at $100-\mathrm{km}$ CLS. Interestingly, some of the biggest differences are located near major topographical features-near the Andes in South America and near the Himalayas in southern China (Figs. 13a,c). Selectively using OLAM's variable resolution capability to better resolve these regions seems likely to be an accurate, computationally efficient way of simulating regional hydroclimate (Fig. 13d; Medvigy et al. 2008). 
While this work focused on monthly to decadal time scales, OLAM is conceptually able to simulate both shorter and longer time scales. Work is currently in progress that will evaluate OLAM's simulation of extreme weather events, with a particular focus on events such as hurricanes that span a range of spatial scales (R. L. Walko et al. 2010, unpublished manuscript). Such studies will take full advantage of the variable-resolution capability demonstrated here to yield high-quality results at a relatively modest computational cost.

An additional next step is the implementation of a fractional cloudiness scheme into OLAM. Realistic, computationally efficient determination of fractional cloudiness remains an area of active research. Independent column models seem to offer the greatest realism (Cahalan et al. 1994; Barker et al. 1999), but are too costly to implement within a GCM. Instead, typical GCM schemes have used the maximum/random overlap assumption of homogeneous clouds (Geleyn and Hollingsworth 1979) although this has been shown to be inappropriate for many cases (Hogan and Illingworth 2000; Mace and Benson-Troth 2002; Barker et al. 2003). A promising alternative for the future that uses an efficient Monte Carlo approach has recently been proposed by Morcrette et al. 2008, and we are experimenting with a variant of this scheme in OLAM.

Acknowledgments. This research was funded by the National Science Foundation Grants NSF ID 0634745 and ATM 0902197. NCEP reanalysis data were provided by the NOAA/OAR/ESRL PSD, Boulder, Colorado, from their Web site online at http://www.cdc.noaa.gov/.

\section{REFERENCES}

Babb, D. M., J. Verlinde, and B. A. Albrecht, 1999: Retrieval of cloud microphysical parameters from $94-\mathrm{GHz}$ radar Doppler power spectra. J. Atmos. Oceanic Technol., 16, 489-503.

Barker, H. W., G. L. Stephens, and Q. Fu, 1999: The sensitivity of domain-averaged solar fluxes to assumptions about cloud geometry. Quart. J. Roy. Meteor. Soc., 125, 2127-2152.

— tive transfer models: interpretation and handling of unresolved clouds. J. Climate, 16, 2676-2699.

Bender, F. A. M., 2008: A note on the effect of GCM tuning on climate sensitivity. Environ. Res. Lett., 3, doi:10.1088/17489326/3/1/014001.

Cahalan, R. F., W. Ridgway, W. J. Wiscombe, and T. L. Bell, 1994: The albedo of fractal stratocumulus clouds. J. Atmos. Sci., 51, 2434-2455.

Collins, W. D., and Coauthors, 2006: The Community Climate System Model version 3 (CCSM3). J. Climate, 19, 2122-2143.

Cotton, W. R., and Coauthors, 2003: RAMS 2001: Current status and future directions. Meteor. Atmos. Phys., 82, 5-29.

Delworth, T. L., and Coauthors, 2006: GFDL's CM2 Global Coupled Climate Models. Part I: Formulation and simulation characteristics. J. Climate, 19, 643-674.
Edwards, A. W. F., 1972: Likelihood. Cambridge University Press, 296 pp.

Geleyn, J.-F., and A. Hollingsworth, 1979: An economical analytical method for the computation of the interaction between scattering and line absorption of radiation. Contrib. Atmos. Phys., 52, 1-16.

Gonçalves, F. L. T., J. A. Martins, and M. A. Silva Dias, 2008: Shape parameter analysis using cloud spectra and gamma functions in the numerical modeling of RAMS during the LBA Project at Amazonian region, Brazil. Atmos. Res., 89, 1-11.

Grell, G. A., and D. Dévényi, 2002: A generalized approach to parameterizing convection combining ensemble and data assimilation techniques. Geophys. Res. Lett., 29, 1693, doi:10.1029/ 2002GL015311.

Guirguis, K. J., and R. Avissar, 2008: An analysis of precipitation variability, persistence, and observational data uncertainty in the western United States. J. Hydrometeor., 9, 843-865.

Harrington, J. Y., 1997: The effects of radiative and microphysical processes on simulated warm and transition season Arctic stratus. Ph.D. thesis, Colorado State University, 289 pp.

— , and P. Q. Olsson, 2001: A method for the parameterization of cloud optical properties in bulk and bin microphysical models: Implications for arctic cloudy boundary layers. Atmos. Res., 57, 51-80.

— T. Reisin, W. R. Cotton, and S. M. Kreidenweis, 1999: Cloud resolving simulations of Arctic stratus. Part II: Transitionseason clouds. Atmos. Res., 51, 45-75.

Hill, G. E., 1974: Factors controlling the size and spacing of cumulus clouds as revealed by numerical experiments. J. Atmos. Sci., 31, 646-673.

Hogan, R. J., and A. J. Illingworth, 2000: Derived cloud overlap statistics from radar. Quart. J. Roy. Meteor. Soc., 126, $2903-$ 2909.

Huffman, G. J., 1997: Estimates of root-mean-square random error for finite samples of estimated precipitation. J. Appl. Meteor., 36, 1191-1201.

—, R. Adler, M. Morrissey, D. Bolvin, S. Curtis, R. Joyce, B. McGavock, and J. Susskind, 2001: Global precipitation at one-degree daily resolution from multisatellite observations. J. Hydrometeor., 2, 36-50.

Jiang, H., G. Feingold, and W. R. Cotton, 2002: Simulations of aerosol-cloud-dynamical feedbacks resulting from entrainment of aerosol into the marine boundary layer during the Atlantic Stratocumulus Transition Experiment. J. Geophys. Res., 107, 4813, doi:10.1029/2001JD001502.

Jones, C., J. Gregory, R. Thorpe, P. Cox, J. Murphy, D. Sexton, and P. Valdes, 2005: Systematic optimisation and climate simulation of FAMOUS, a fast version of HadCM3. Climate Dyn., 25, 189-204.

Kalnay, E., and Coauthors, 1996: The NCEP/NCAR 40-Year Reanalysis Project. Bull. Amer. Meteor. Soc., 77, 437-471.

Lilly, D. K., 1962: On the numerical simulation of buoyant convection. Tellus, 14, 148-172.

Liu, Y., and R. Avissar, 1996: Sensitivity of shallow convective precipitation induced by land surface heterogeneities to dynamical and cloud microphysical parameters. J. Geophys. Res., 101 (D3), 7477-7497.

Mace, G. G., and S. Benson-Troth, 2002: Cloud-layer overlap characteristics derived from long-term cloud radar data. J. Climate, 15, 2505-2515.

Medvigy, D., R. L. Walko, and R. Avissar, 2008: Modeling interannual variability of the Amazon hydroclimate. Geophys. Res. Lett., 35, L15817, doi:10.1029/2008GL034941. 
Morcrette, J.-J., H. W. Barker, J. S. Cole, M. J. Iacono, and R. Pincus, 2008: Impact of a new radiation package, McRad, in the ECMWF Integrated Forecasting System. Mon. Wea. Rev., 136, 4773-4798.

Murphy, J. M., and Coauthors, 2004: Quantification of modeling uncertainties in a large ensemble of climate change simulations. Nature, 430, 768-772.

Meyers, M. P., R. L. Walko, J. Y. Harrington, and W. R. Cotton, 1997: New RAMS cloud microphysics parameterization. Part II: The two-moment scheme. Atmos. Res., 45, 3-39.

Nachamkin, J., and W. R. Cotton, 2000: Interaction between a developing mesoscale convective system and its environment. Part II: Numerical simulation. Mon. Wea. Rev., 128, 12251244.

Norris, P. M., and A. M. da Silva, 2007: Assimilation of satellite cloud data into the GMAO finite-volume data assimilation system using a parameter estimation method. Part I: Motivation and algorithm description. J. Atmos. Sci., 64, 38803895.

Pielke, R. A., and Coauthors, 1992: A Comprehensive Meteorological Modeling System-RAMS. Meteor. Atmos. Phys., 49, 69-91.

Press, W. H., S. A. Teukolsky, W. T. Vetterling, and B. P. Flannery, 1992: Numerical Recipes in C: The Art of Scientific Computing. Cambridge University Press, 994 pp.

Ramanathan, V., R. D. Cess, E. F. Harrison, P. Minnis, B. R. Barkstrom, E. Ahmad, and D. Hartmann, 1989: Cloud-radiative forcing and climate: Results from the Earth Radiation Budget Experiment. Science, 243, 57-63.

Randall, D. A., and Coauthors, 2007: Climate models and their evaluation. Climate Change 2007: The Physical Basis, S. Solomon et al., Eds., Cambridge University Press, 608-613.

Reynolds, R. W., N. A. Rayner, T. M. Smith, T. C. Stokes, and W. Wang, 2002: An improved in situ and satellite SST analysis for climate. J. Climate, 15, 1609-1625.

Richey, J. E., R. L. Victoria, E. Salati, and B. R. Forsbert, 1991: The biogeochemistry of a major river system: The Amazon case study. Biogeochemistry of Major World Rivers, E. T. Degens, S. Kempe, and J. E. Richey, Eds., John Wiley and Sons, 57-74.

Severigns, C. A., and W. Hazeleger, 2005: Optimizing parameters in an atmospheric general circulation model. J. Climate, 18, 3527-3535.

Shimpo, A., M. Kanamitsu, and S. F. Iacobellis, 2008: Comparison of four cloud schemes in simulating the seasonal mean field forced by the observed sea surface temperature. Mon. Wea. Rev., 136, 2557-2575.
Simmonds, I., and K. Keay, 2000: Mean Southern Hemisphere extratropical cyclone behavior in the 40-Year NCEP-NCAR reanalysis. J. Climate, 13, 873-885.

Stainforth, D. A., and Coauthors, 2005: Uncertainty in predictions of the climate response to rising levels of greenhouse gases. Nature, 433, 403-406.

Stevens, B., W. R. Cotton, G. Feingold, and C.-H. Moeng, 1998: Large-eddy simulations of strongly precipitating, shallow, stratocumulus-topped boundary layers. J. Atmos. Sci., 55, $3616-3638$

Tsay, S.-C., and K. Jayaweera, 1984: Physical characteristics of Arctic stratus clouds. J. Climate Appl. Meteor., 23, 584-596.

Vallina, S. M., R. Simó, and S. Gassó, 2006: What controls CCN seasonality in the Southern Ocean? A statistical analysis based on satellite-derived chlorophyll and $\mathrm{CCN}$ and model-estimated $\mathrm{OH}$ radical and rainfall. Global Biogeochem. Cycles, 20, GB1014, doi:10.1029/2005GB002597.

Walko, R. L., and R. Avissar, 2008a: The Ocean-Land-Atmosphere Model (OLAM): Shallow-water tests. Mon. Wea. Rev., 136, 4033-4044.

, and - 2008b: The Ocean-Land-Atmosphere Model (OLAM): Formulation and tests of the nonhydrostatic dynamic core. Mon. Wea. Rev., 136, 4045-4062.

, W. R. Cotton, M. P. Meyers, and J. Y. Harrington, 1995: New RAMS cloud microphysics parameterization. Part I: The singlemoment scheme. Atmos. Res., 38, 29-62.

, G. Feingold, and B. Stevens, 2000a: Efficient computation of vapor and heat diffusion between hydrometeors in a numerical model. Atmos. Res., 53, 171-183.

, and Coauthors, 2000b: Coupled atmosphere-biophysicshydrology models for environmental modeling. J. Appl. Meteor., 39, 931-944.

Wielicki, B. A., B. R. Barkstrom, E. F. Harrison, R. B. Lee, G. L. Smith, and J. E. Cooper, 1996: Clouds and the Earth's Radiant Energy System (CERES): An Earth observing system experiment. Bull. Amer. Meteor. Soc., 77, 853-868.

—_, and Coauthors, 2002: Evidence for large decadal variability in the tropical mean radiative energy budget. Science, 295, 841-844

Xie, P., and P. A. Arkin, 1997: Global precipitation: A 17-year monthly analysis based on gauge observations, satellite estimates, and numerical model outputs. Bull. Amer. Meteor. Soc., 78, 2539-2558.

Yin, X., A. Gruber, and P. Arkin, 2004: Comparison of the GPCP and CMAP merged gauge-satellite monthly precipitation products for the period 1979-2001. J. Hydrometeor., 5, 1207-1222. 